\title{
Cytomegalovirus in female patients attending a VD clinic
}

\author{
F. E. WILLMOTT \\ Leicestershire Royal Infirmary, Leicester LE1 5WW
}

Cytomegalovirus (CMV) is now recognized as an important congenital infection. It is probably commoner than rubella (Hanshaw, Schultz, Melish, and Dudgeon, 1972). As many as 4,000 congenitally infected babies may be born in the United Kingdom each year, of which 10-15 per cent. will have clinical cytomegalic inclusion disease (Tobin, 1972). The incidence of cytomegalovirus in women, reported in most cases from antenatal clinics, has varied between 3 and 18 per cent. depending on the country of origin (Table I).

Recently the possibility that the virus may be sexually transmitted has been suggested (Lang and Kummer, 1972), and a recent study from the U.S.A. has shown a high incidence in VD clinic patients (Jordan, Rousseau, Noble, Stewart, and Chin, 1973). Walker and Tobin (1970) reported an incidence of 4 per cent. in non-pregnant women, some of whom were patients at a VD clinic. Mair (1974) found an incidence of 3.2 per cent. in patients attending a VD clinic and of $2 \cdot 1$ per cent. in patients at a family planning clinic.

The present study was undertaken to find the incidence of CMV in the cervix in patients at a VD clinic and if possible to assess the role of sexual transmission.

Received for publication November 29, 1974

\section{Methods}

531 female patients attending the Special Clinic of the Leicester Royal Infirmary were the subjects of the study.

A history was taken with special reference to previous 'glandular fever' type illnesses or sore throats.

\section{Specimens}

Sterile cotton-tipped swabs were used to obtain cervical specimens. These were immersed in virus transport medium and sent for culture. Routine smears and cultures were also taken for $N$. gonorrhoeae, $T$. vaginalis, and C. albicans.

Blood was taken at the initial attendance and stored. If CMV was found, a CMV complement-fixation test (CMVCFT) was carried out on the serum.

If possible the male consorts of patients with $\mathrm{CMV}$ were examined. A urethral swab was taken for virus culture and in a few cases a throat swab, urine, and seminal fluid were also cultured. Blood was taken for CMVCFT.

\section{Transport medium}

The medium consisted of Hanks's solution with 20 per cent. of 50 per cent. sorbitol, 10 per cent. inactivated calf serum, 5 per cent. of 4.4 bicarbonate, and neomycin. $2 \mathrm{ml}$. amounts were made up in bijou bottles.

Virus culture

The specimens were inoculated within $24 \mathrm{hrs}$ (usually on the same day as they were taken). $0.2 \mathrm{ml}$. of inoculum was put into two tubes of human embryonic lung cells (HEL).

TABLE I Incidence of CMV in antenatal patients

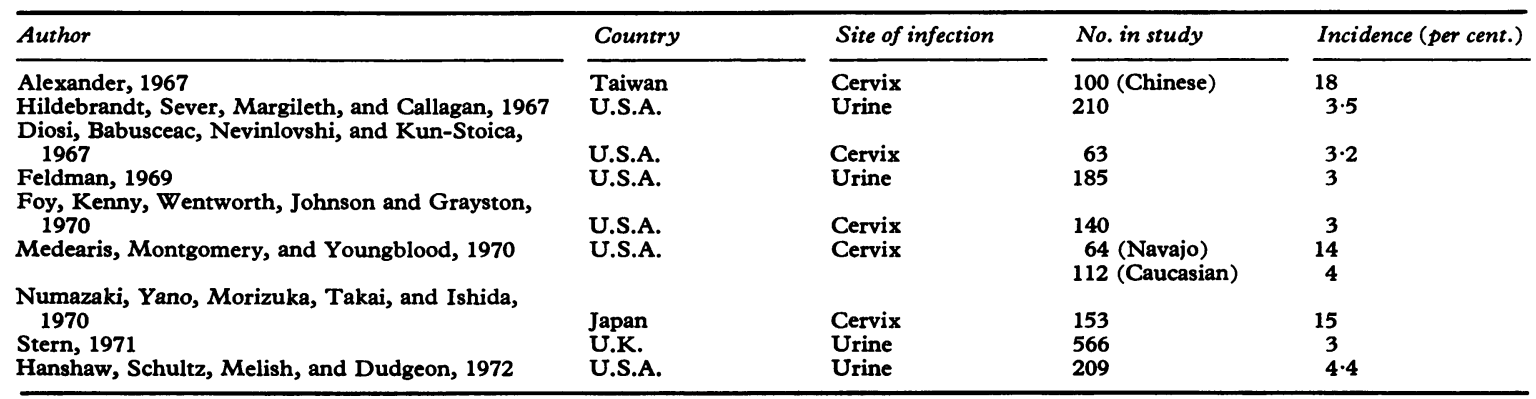


The cells were grown in Eagle's basic medium (BME) with 10 per cent. foetal calf serum and maintained with BME with 5 per cent. foetal calf serum (changed twice weekly). CMV was recognized by its characteristic cytopathic effect and failure to grow on non-fibroblastic cell lines. The cell cultures were left for 4 weeks. Positive results were obtained at periods ranging from 3 to 26 days.

\section{Findings}

Of the 531 patients, 35 were positive for CMV (6.6 per cent.). Their ages ranged from 16 to 33 years (mean 21).

28 of the 531 patients were positive for Herpes virus hominis (5.3 per cent.).

\section{Oral contraceptives}

Excluding six who were pregnant and one who attended post-natally, twenty of the 28 patients with CMV were taking oral contraceptives ( 71 per cent.). This compares with 218 out of the 513 in the whole group (42.5 per cent.). This is statistically significant $(P<0.05)$.

\section{Pregnancy}

Six patients were pregnant at the time of isolation of CMV. All six babies showed no clinical evidence of cytomegalic inclusion disease and CMV was not isolated from throat swab and urine in the three who were tested. One patient was positive 6 weeks postnatally but $\mathrm{CMV}$ was not isolated from throat swab or urine in the baby (see Table II).

TABLE II CMV and pregnancy

\begin{tabular}{|c|c|c|c|}
\hline Trimester & $I$ & $I I$ & $I I I$ \\
\hline Culture positive & 4 & - & 2 \\
\hline Culture negative from baby & 3 & - & $\bar{a}$ \\
\hline Clinically normal baby & 4 & - & 2 \\
\hline
\end{tabular}

One baby examined at 6 weeks culture negative

\section{Persistence of isolation}

In twenty cases $\mathrm{CMV}$ continued to be recovered for periods up to 10 months. Repeat cultures were negative in only four cases. In the other eleven cases repeat cultures were not performed (nine defaulted after initial attendance and two were seen again but unfortunately virus cultures were not repeated).

\section{Associated infections}

28 out of 35 patients ( 80 per cent.) had associated infections. There was a high incidence of genital warts ( 26 per cent.), compared with about 6 per cent. for all patients (see Table III).

\section{Symptoms and signs}

Only one patient had symptoms related to acquired $\mathrm{CMV}$ infection and presented as a case of $\mathrm{CMV}$
TABLE III Associated infections in 35 patients

\begin{tabular}{ll}
\hline Infective organism & No. of cases \\
\hline N. gonorrhoeae & 5 \\
T. vaginalis & 2 \\
C. albicans & 9 \\
N. gonorrhoeae and T. vaginalis & 3 \\
N. gonorrhoeae and C. albicans & 3 \\
$N$. gonorrhoeae, T. vaginalis, and C. albicans & 4 \\
T. vaginalis and C. albicans & 1 \\
C. albicans and Herpes virus hominis & 1 \\
\hline Total & 28 \\
\hline
\end{tabular}

SUMMARY

$N$. gonorrhoeae 15 (43 per cent.)

Trichomonas 10 (28 per cent.)

Candida 18 (51 per cent.)

Genital warts 9 (26 per cent.)

mononucleosis (vide infra). Another patient had a history of Paul-Bunnell positive infectious mononucleosis 3 months before attendance and recurrent sore throats subsequently. Throat swab as well as the cervix were positive for CMV; the white blood cells showed 58 per cent. lymphocytes but no atypical mononuclear cells.

No symptoms could be related to the presence of $\mathrm{CMV}$ in the cervix. In several cases (after treatment of associated infections) a cervicitis was present and the cervix bled easily on examination. One patient had atypical cells in the cervical smear but this was negative when the test was repeated after 3 months; she is being kept under surveillance.

\section{Serology}

A CMVCFT was performed on 23 of the patients with positive CMV cultures and was positive in all; titres ranged from 1:8 to $1: 256$. Eighteen had repeat CMVCFTs but none showed any marked change in titre.

\section{Consorts}

Seven male consorts were seen, In all seven urethral cultures were negative, and in three, throat, urine, and seminal fluid cultures were also negative. The consort of the patient with CMV mononucleosis had negative tests. The female with a positive throat swab admitted oro-genital contact but her consort was negative in all sites. In four male consorts who had CMVCFT tests they were positive in titres ranging from $1: 4$ to $1: 64$.

\section{Case of CMV mononucleosis}

A Caucasian female aged 17 years presented complaining of dysuria for one week. She had been given metronidazole 4 weeks previously by her general practitioner for a sore throat and mouth ulcers. She admitted regular sexual contact with one consort for the previous year. Examination showed a slight pharyngitis but no lymphadenopathy. Urethral and cervical smears showed Gramnegative diplococci but cultures for $N$. gonorrhoeae were 
negative. Culture for $C$. albicans was positive. She was treated with cotrimoxazole by mouth and nystatin pessaries. Virus culture was positive for CMV within 3 days and showed multiple foci indicating a heavy infection. One week later, throat swab and urine were negative for CMV, but the white blood count was 8,100 with 37 per cent. polymorphs, 36 per cent. lymphocytes, 5 per cent. monocytes, and 22 per cent. atypical mononuclear cells. The Paul-Bunnell test was negative but a CMVCFT was positive $1: 64$. She was seen again after a further 2 weeks when CMV was again isolated from the cervix and she still had 11 per cent. atypical mononuclears in the blood film. Unfortunately she then defaulted.

Her consort was examined and found to have nonspecific urethritis. Urethral swab, throat swab, urine, and seminal fluid were negative on culture for CMV. His CMVCFT was positive $1: 4$.

\section{Discussion}

The isolation rate of 6.6 per cent. is higher than that found in antenatal patients in the United Kingdom and in most reports from the U.S.A. It is not as high as that reported from a VD clinic in the U.S.A. where 16 out of 120 cases ( 13.3 per cent.) were positive for CMV (Jordan and others, 1973).

The persistence of isolation suggests that these are chronic infections.

The absence of any overt congenital infection in the seven babies born to infected mothers supports the hypothesis that primary infection is necessary in pregnancy for the foetus to be affected (Hanshaw and others, 1972).

The high frequency of women taking oral contraceptives among those with CMV may indicate that the 'pill' reactivates a latent infection, as has been suggested for pregnancy (Montgomery, Youngblood, and Medearis, 1972).

There is a high incidence of associated infections (80 per cent.). This may indicate that persistent infection of the cervix with CMV predisposes to infection with other organisms. This would explain the higher incidence in patients attending a VD clinic.

In this series no evidence of transmission by sexual intercourse was obtained. It seems likely that examination of patients with a primary infection and their consorts would be necessary to obtain proof of sexual transmission.

\section{Summary}

A study of 531 female patients attending a venereal disease clinic was undertaken to assess the incidence of cytomegalovirus (CMV) in the cervix.

The findings were as follows:

(1) 35 of 531 patients had positive cervical cultures for CMV (6.6 per cent.).

(2) 28 of 531 patients were positive for Herpes virus hominis ( $5 \cdot 3$ per cent.).
(3) Excluding those who were pregnant, 20 of 28 with CMV were taking oral contraceptives (71 per cent.).

(4) Seven babies born to infected mothers showed no signs of cytomegalic inclusion disease.

(5) 28 of 35 with $\mathrm{CMV}$ had associated genital infections (80 per cent.).

(6) Positive cultures were obtained in twenty cases for periods up to 10 months.

(7) The CMV complement-fixation test was positive in all 23 patients with positive CMV cultures who were tested.

(8) Seven male consorts were examined but CMV was not isolated from any of them.

(9) A case of CMV mononucleosis was detected.

It is suggested that the higher incidence in patients attending a VD clinic is due to the presence of CMV in the cervix predisposing to other genital infections rather than to its being sexually transmitted.

I wish to express my thanks to Dr. Helene J. Mair for the virological studies done at the Public Health Laboratories, Groby Road Hospital, Leicester, and for her assistance with this paper.

This study was made possible by a grant from the Department of Health and Social Security.

\section{References}

Alexander, E. R. (1967) Ped. Res., 4, 461

Diosi, P., Babusceac, L., Nevinglovshi, O., and KunStoicu, G. (1967) Lancet, 2, 1063

Feldman, R. A. (1969) Amer. F. Dis. Child., 117, 517

FOY, H. M., KeNNY, G. E., WENTWORTH, B. B., JOHNSON, W. L., and Grayston, T. T. (1970) Amer. F. Obstet. Gynec., 106, 635

Hanshaw, J. B., Schultz, F. W., Melish, M. M., and DUdGEON, J. A. (1972) In 'Intrauterine Infections', CIBA Foundation Symposium, New Series, No. 10, p. 23. Churchill, London.

Hildebrandt, R. J., Sever, J. L., Margileth, A. M., and Callaghan, D. A. (1967) Amer. F. Obstet. Gynec., 98, 1125

Jordan, M. C., Rousseau, W. E., Noble, G. R., Stewart, J. A., and ChIN, T. D. Y. (1973) New Engl. F. Med., 288, 932

LANG, D. J., and Kummer, J. F. (1972) Ibid., 287, 756

MaIR, H. J. (1974) Personal communication

MEdearis, D. N., Montgomery, R., and Youngblood, L. (1970) Ped. Res., 4, 461

MONTGOMERY, R., Youngblood, L., and MEDEARIS, D. N. (1972) Pediatrics, 49, 524

Numazaki, Y., Yano, N., Morizuka, T., TakaI, S., and IsHIDA, N. (1970) Amer. F. Epidem., 91, 410

Stern, H. (1971) 'Proc. XIII int. Congr. Paediatrics', vol. 6, p. 301. Academy of Medicine, Vienna

ToBIN, J. O'H. (1972) In 'Intrauterine Infections', CIBA Foundation Symposium, No. 10, New Series, p. 32. Churchill, London

WALKER, G. H., and TOBIN, J. O'H. (1970) Arch. Dis. Childh., 45, 513 